\title{
MAKNA KEBANGKITAN YESUS BERDASARKAN SURAT-SURAT PAULUS
}

\author{
Resa Junias $^{* 1}$, Dorce Sondopen ${ }^{2}$ \\ ${ }^{1,2}$ Sekolah Tinggi Teologi Excelsius \\ *resajunias28@gmail.com
}

\begin{abstract}
Basically, Jesus was willing to offer himself to come down to earth to teach the gospel to every human being and was willing to be tortured, crucified, and died to atone for human sins. The purpose of this research is to answer the question: What does God want about His resurrection? How important is the resurrection of Jesus for the lives of believers? What effect will the resurrection of Jesus Christ have on the lives of believers? The answer was: (1) His bodily resurrection and eternity. Everything is possible because Christ, after He rose from the dead, did not die again, in other words, He lives and continues to live. The resurrection of Christ happened a transfer of power, Christ went from being ruled by death to being ruler over death. (2) Without the resurrection, Christian faith is not possible. His disciples are only symbols of defeat and destruction. Without the resurrection, Jesus' position as Messiah and King would be inexplicable. Without the resurrection, the outpouring of the Holy Spirit would leave an inexplicable mystery. Without the resurrection, the source of the disciples' testimony was lost. (3) The impact of the resurrection of Jesus Christ for the lives of believers is that as long as man is in God, whatever he does, all his efforts in God, will receive a reward or reward from God.
\end{abstract}

Keywords: Jesus, resurrection, Paul's letters, reward.

\begin{abstract}
Abstrak
Pada dasarnya Yesus rela mempersembahkan diri-Nya untuk turun ke bumi guna mengajarkan injil bagi setiap manusia dan rela disiksa, serta disalibkan, dan mati bagi menebus dosa manusia. Tujuan penelitian ini menjawab pertanyaan: Apakah yang Tuhan inginkan tentang kebangkitanNya? Bagaimana pentingnya kebangkitan Yesus untuk kehidupan orang percaya? Apa dampak kebangkitan Yesus Kristus bagi kehidupan orang percaya? Jawabnya adalah: (1) Kebangkitan tubuhnya dan berlanjut dalam kekekalan. Semuanya dapat terjadi karena Kristus, sesudah Ia bangkit dari antara orang mati, tidak mati lagi, dengan kata lain, Ia hidup dan terus hidup. Kebangkitan Kristus terjadi peralihan kekuasaan, Kristus beralih dari dikuasai oleh maut menjadi penguasa atas maut. (2) Tanpa kebangkitan, iman Kristen tidak mungkin muncul. Murid-murid-Nya hanyalah simbol kekalahan dan kehancuran. Tanpa kebangkitan, posisi Yesus sebagai Mesias dan Raja tidak akan terjelaskan. Tanpa kebangkitan, pencurahan Roh Kudus akan meninggalkan misteri yang tidak dapat dijelaskan. Tanpa kebangkitan, sumber kesaksian murid-murid hilang. (3) Dampak kebangkitan Yesus Kristus bagi kehidupan orang percaya adalah selama manusia ada di dalam Tuhan, apapun yang ia kerjakan, semua jerih payahnya dalam Tuhan, akan mendapat balasan atau upah dari Tuhan.
\end{abstract}

Kata kunci: Yesus, kebangkitan, surat-surat Paulus, upah. 


\section{PENDAHULUAN}

Alkitab, khususnya Perjanjian Baru, adalah kitab yang dibaca oleh orang Kristen setiap hari, paling tidak setiap hari Minggu, apalagi Alkitab telah diterjemahkan ke dalam berbagai bahasa, termasuk bahasa daerah sehingga memudahkan bagi semua warga gereja membacanya. Walau demikian, isinya tidak selalu mudah dimengerti oleh pembaca masa kini karena tulisan - tulisan dalam Perjanjian Baru ditulis di dalam bahasa, konteks sejarah, keadaan sosial politik tertentu, dan ditujukan kepada kelompok pembaca di masa lampau dengan latar belakang budayanya dan pergumulan teologisnya sendiri. Padahal inti berita Alkitab dalam hal ini, Perjanjian Baru tidak hanya relevan bagi kehidupan umat pembaca di masa lampau tetapi juga bagi kehidupan umat pembaca di masa kini. Oleh sebab itu yang menjadi pusat pemberitaan adalah Yesus Kristus yang telah bangkit dari antara orang mati dan yang adalah Tuhan dan Juruselamat dunia. Yesus Kristus merupakan warta gembira. Warta itu disampaikan melalui firman Allah. Firman yang hidup itu adalah Yesus Kristus. ${ }^{1}$

Yesus merupakan teladan hidup yang mesti dijadikan contoh oleh orang-orang Kristen dalam kehidupannya sehari-hari. Jadi, kalau Yesus hidup menderita maka orang Kristen pun hidup dalam penderitaanNya. $^{2}$ Disalibkan berarti Yesus tidak saja menderita tetapi manusia yang lain (orang percaya) juga menderita dalam nama-Nya. ${ }^{3}$

Dalam artikel ini, penulis akan membahas tentang makna kebangkitan dalam Perjanjian Baru. Kata "bangkit" dapat

\footnotetext{
${ }^{1}$ M. Abudullah (2017), "Yesus Juru Selamat dalam Agama Kristen", Tasamuh: Jurnal Studi Islam, 9(2), 339-376.

${ }^{2}$ Harianto GP, (2019), “ Mission in Suffering Context”, Jurnal Excelsius Deo, 3(2), 76.

${ }^{3}$ Ibid. 79.
}

diartikan sebagai "bangun", dan kata "kebangkitan" itu sendiri diartikan "kebangunan". Ciri dan kejutan khas berita Kristen pertama ialah penekanannya pada kebangkitan. Gagasan Kristen tentang kebangkitan harus dibedakan baik dari gagasan Yunani maupun dari gagasan Yahudi. Orang Yunani menganggap tubuh sebagai hambatan kehidupan sejati, dan mereka mengharapkan saatnya jiwa akan bebas dari kungkungannya. Mereka memahami hidup setelah mati sebagai keamartaan jiwa, tapi mereka dengan kuat menolak segala gagasan tentang kebangkitan (bnd olok-olok atas khotbah Paulus dalam Kis. 17:32). Orang Yahudi meyakini teguh harkat-harkat tubuh dan menganggapnya tidak akan binasa. Jadi mereka berharap bahwa tubuh akan dibangkitkan. Tapi mereka berpikir bahwa yang dibangkitkan adalah tepat tubuh yang sama dengan tubuh yang mati. Orang Kristen berpikir tentang tubuh yang dibangkitkan, tapi sebagai yang diubah sedemikian rupa sehingga "tepat guna" bagi kehidupan yang akan datang, yang begitu berbeda dari kehidupan kini (1 Kor. 15:42). ${ }^{4}$ Jadi, gagasan Kristen adalah khas.

Bulan Maret-April setiap tahun umat Kristiani merayakan hari kematian Yesus yang disusul dengan hari kebangkitan-Nya, yang kita sebut Paskah. Tanggalnya selalu berubah-ubah setiap tahunnya, tetapi harinya adalah sama, yaitu Jumat: hari kematian dan Minggu: hari kebangkitan Yesus. Paskah adalah hari Minggu pertama setelah bulan pertama setelah bulan purnama dalam bulan Nisan. Bulan Nisan adalah bulan pertama menurut kalender Yahudi, yang biasa terdapat dalam bulan Maret atau April.

${ }^{4}$ J.D. Douglas, Ensiklopedia Alkitab Masa kini (Jakarta: Yayasan Komunikasi Bina Kasih, 1997), 24.

Excelsis Deo: Jurnal Teologi, Misiologi dan Pendidikan 
Kematian dan kubur telah kalah. Kematian tidak sanggup menahan Yesus dan kuburan yang bertutupkan batu besar pun tidak mampu menjaga Yesus supaya jangan keluar dari dalamnya. Kubur telah menjadi kosong, "Ia telah bangkit, Ia tidak ada disini." Demikian pemberitaan malaikat kepada perempuan-perempuan yang berada di tempat kubur yang kosong itu (Mrk. 16:6). Kubur yang kosong telah menjadi saksi atau bukti kebangkitan Yesus. Kebangkitan Yesus pun sesuai dengan Kitab Suci. Dalam Perjanjian Lama terdapat beberapa ungkapan "Pada hari yang ketiga" (Kej. 22:4; 42:18; Kel. 19:11, 16; Yos. 2:16; 2 Raj. 20:5, 8; Est. 5:1; Hos. 6:2-3). "Hari Ketiga" menunjukkan tindakan Allah terhadap Israel yang baik atau orang-orang yang benar. Sebagai contoh, lihat pada pengalaman Hizkia, yang menderita sakit. Ia berserah kepada Tuhan dan Tuhan mendengarkan doanya. Tuhan berpesan kepadanya melalui Yesaya (2 Raj. 20:5). Pengalaman Yunus di dalam perut ikan tiga hari tiga malam lamanya, kemudian dia keluar dari perut ikan (Yun. 1-2). Kejadian itu merupakan nubuatan akan kebangkitan Yesus, juga diakui oleh Yesus sendiri (Mat. 12:38-42; Luk. 11:29-32). Dalam Hosea 6:2 dapat juga dilihat adanya nubuat tentang kebangkitan Yesus pada hari ketiga, walaupun nama Yesus tidak disebut didalamnya. ${ }^{5}$ Sebagaimana kematian Yesus telah direncanakan, demikian juga kebangkitan-Nya, sesuai dengan Kitab Suci, maka nubuat itu terealisasi dengan baik. Tidak ada nubuat Tuhan yang gagal. Ia telah merencanakan, dan Ia juga yang melakukannya. "Allah telah membangkitkan Dia dari antara orang mati” (Rm. 10:9). Dukacita telah menjadi sukacita. ${ }^{6}$

\footnotetext{
${ }^{5}$ A. M. Hunther, Tema-tema Perjanjian Baru (Jakarta: BPK Gunung Mulia, 2009), 11-12.

${ }^{6}$ Ibid., 9-12.
}

Dalam hal ini, tujuan penelitian adalah menjelaskan makna kebangkitan Yesus dalam Kitab Perjanjian Baru yang telah ditulis oleh Rasul-Rasul dalam dunia Perjanjian Baru berikut: Apakah yang Tuhan inginkan tentang kebangkitan-Nya? Bagaimana pentingnya kebangkitan Yesus untuk kehidupan orang percaya? Apa dampak kebangkitan Yesus Kristus bagi kehidupan orang percaya?

\section{METODE}

Jenis penelitian yang digunakan adalah kualitatif dengan pendekatan deskriptif bertujuan untuk menyajikan informasi $^{7}$ dengan metode untuk menggambarkan suatu hasil penelitian. Namun, hasil gambaran tersebut tidak digunakan untuk membuat kesimpulan yang lebih umum.

\section{PEMBAHASAN}

\section{Makna kebangkitan bagi manusia}

Peristiwa kematian Tuhan Yesus di atas kayu salib karena dosa-dosa seluruh isi dunia mempunyai makna teologis yang tidak terkira pentingnya. Menurut penjelasan Stephen Tong, dalam Bahasa Indonesia ada satu kalimat pembukaan yang tidak diterjemahkan ke dalam ayat (1 Kor. 15:5457) tersebut, yaitu kalimat, "pada saat itu Yesus berkata ...”. Ada tiga hal yang sudah ditekankan olehnya, yaitu: Saat paling lelah secara fisik, saat paling sengsara, dan saat paling sendiri. De Kamp mencoba menggambarkan penderitaan Yesus dengan sebuah pernyataan, "Selama berjam-jam, Dia

${ }^{7}$ H.B. $\quad$ Sutopo, Metodologi Penelitian Kuantitatif (Surakarta: Universitas Sebelas Maret Press, 2006), 25. 
bagaikan segumpal daging mentah yang tergantung di atas kayu salib."8

$$
\text { Orang percaya meyakini Kristus }
$$

tidak tinggal dalam kematian (maut), melainkan Dia juga bangkit mengalahkan maut dan hidup. Dalam Roma 6:9 merupakan penegasan dari kebenaran yang dinyatakan dalam ayat 8 . Kehidupan orang percaya Bersama Kristus adalah realitas masa kini dan berlangsung terus sepanjang hidupnya, bahkan sampai kebangkitan tubuhnya dan berlanjut dalam kekekalan. Semuanya dapat terjadi karena Kristus, sesudah Ia bangkit dari antara orang mati, tidak mati lagi, dengan kata lain, Ia hidup dan terus hidup. Kata "berkuasa" yang diterjemahkan dari kata kurieuei menggambarkan maut sebagai tuan atau penguasa. Dalam kebangkitan Kristus terjadi peralihan kekuasaan, Kristus beralih dari dikuasai oleh maut menjadi penguasa atas maut. Maut bukan hanya tidak berkuasa lagi atas Dia, tetapi justru oleh kebangkitan Kristus maut takluk di bawah kekuasaan Kristus. ${ }^{9}$

\section{Kebangkitan Yesus}

Kebangkitan Yesus Kristus dari antara orang mati adalah salah satu pokok terpenting dari sekian pokok-pokok pengajaran (azas) kekristenan, karena jika Yesus tidak bangkit dari antara orang mati maka pokok-pokok ajaran kekristenan lainnya tidak berarti. Kebangkitan Yesuslah yang memberikan makna serta arti dari seluruh pokok pengajaran kekristenan dan

${ }^{8}$ A.F. Lele \& R. Panggarra. (2015), "Makna Tujuh Ungkapan Yesus di Salib bagi Orang Percaya". Jurnal Jaffray, 13(2), 285-316. https://doi.org/10.25278/jj71.v13i2.181.

${ }^{9}$ H. Frederik. (2015), "Konsep Persatuan dengan Kematian dan Kebangkitan Kristus berdasarkan Roma 6:1-14", Jurnal Jaffray, 13(2), 215-248. https://doi.org/10.25278/jj71.v13i2.179. seluruh kegiatan umat kristiani. Kebangkitan Yesus adalah pemberi motivasi, semangat, harapan, kepastian keselamatan serta kekuatan kepada umat kristiani di seluruh muka bumi dari zaman ke zaman untuk hidup memuliakan Tuhan dan melayani sekalipun akan menghadapi berbagai ancaman maut. Kebangkitan Kristus sangat penting dalam serta dipahami oleh umat kristiani agar tetap hidup setia beriman kepada Tuhan karena kebangkitan Yesus menjamin kebangkitan setiap orang beriman kepada Tuhan Yesus.

Poerwadarminta menulis bahwa Kebangkitan berasal dari kata dasar bangkit yang berarti "bangun untuk hidup kembali". ${ }^{10}$ Kata yang dipakai dalam Perjanjian Baru mengenai kebangkitan adalah Anastasia, yang berasal dari kata kerja anistemi yang berarti bangkit. Selain itu dipakai juga kata egeiro yang berarti bangun. Kata kebangkitan sangat banyak di jumpai dalam Perjanjian Baru dan sangat penting dalam ajaran agama Kristen sebab tanpa kebangkitan Yesus maka tidak akan ada Kekristenan. Kebangkitan Yesus Kristus adalah berita sentral dari agama Kristen sebab melalui kebangkitan Yesus Kristus kita mempunyai hidup kekal dalam Yesus yang telah bangkit itu. Verkuyl menulis dalam bukunya, "Aku Percaya" bahwa kebangkitan Yesus adalah bukti dari pihak Allah, bahwa Yesus Kristus sungguhsungguh anak Allah, dan suatu bukti nyata, bahwa Yesus adalah Kristus, Sang Mesias. ${ }^{11}$ Kebangkitan Yesus adalah proklamasi oleh Allah tentang arti sengsara dan kematian Yesus di kayu salib yang membawa perdamaian dan keselamatan.

\footnotetext{
${ }^{10}$ W.J.S. Poerwadarminta, Kamus Umum Bahasa Indonesia (Jakarta: Balai Pustaka, 1984), 86.

${ }^{11}$ J. Verkuyl, Aku Percaya (Jakarta: BPK Gunung Mulia, 1995), 158.
} 
Kemudian ia menulis bahwa kebangkitan Yesus itu berarti Yesus lebih kuat daripada kekuasaan dosa dan iblis. Yesus yang unggul dan menang untuk kita. Manusia pada umumnya telah dibelenggu oleh dosa dan tidak berdaya untuk melawan dosa. Namun bila mana kita hidup dalam kebangkitan Yesus itu berarti keinginan dosa/iblis dikalahkan dan kita mulai hidup dalam hidup baru dan kemenangan. Kebangkitan Yesus mengandung arti bahwa: (1) Dalam kebangkitan Kristus dinyatakan kemenangan-Nya atas kuasakuasa dosa, maut dan iblis; maka kebangkitan Kristus meyakinkan dan memberi jaminan kepada kita tentang realitas pengampunan dosa. (2) Dengan kebangkitan-Nya, persekutuan dengan Kristus yang sudah bangkit itu berarti bahwa kini dan di sini kita bangkrt hidup untuk meniulai hidup baru.(3) Kebangkitan Kristus adalah suatu jaminan bagi kita akan kebangkitan kita yang berbahagia, yakni di dalam kerajaan Allah yang akan dinyatakan.

Kebangkitan Yesus bahwa dengan membangkitkan Yesus dari antara orang mati, Tuhan Allah untuk kedua kalinya memberikan anak-Nya kepada manusia. Selanjutnya beliau mengemukakan bahwa kebangkitan Yesus itu suatu kejadian sejarah yang historis, yang bersejarah, yang dihubungkan dengan iman. Rasul Paulus dengan tegas mengemukakan tentang arti kebangkitan Yesus bahwa jikalau Kristus tidak dibangkitkan, maka sia-sialah kepercayaan orang percaya dan orang percaya masih hidup dalam dosa (1 Kor. 15:17,18,26). Begitu besar arti dan makna dari kebangkitanYesus Kristus bagi setiap orang beriman. Inilah karya Kristus yang sangat dalam sehingga sulit diterima bagi orang yang mengandalkan otaknya sematamata. ${ }^{12}$ Bukti bahwa Tuhan Yesus bangkit:

\section{Penampakan Yesus Pasca Kebangkitan}

Bukti kebangkitan Yesus adalah penampakan yang Yesus lakukan kepada banyak orang. ${ }^{13}$ Ia bangkit secara fisik bukan hanya rohani. Yesus memiliki daging dan tulang (Luk. 24:39), makan ikan (Luk. 24: 42-43) dan mendorong Tomas yang meragukan Dia bangkit untuk menusukkan jarinya ke lubang-lubang bekas paku di tangan dan kaki, serta bekas tusukan tombak di lambung-Nya (Yoh. 20:27). Rasul Paulus, walaupun bukan seorang saksi mata di kubur yang kosong, telah mendengar sendiri kesaksian banyak orang yang telah melihat Yesus yang sudah bangkit, bahkan ia sendiri telah bertemu dengan Yesus. Ia mencatat dalam 1 Korintus 15: 3-8 demikian: "Sebab yang sangat penting telah kusampaikan kepadamu, yaitu apa yang telah kuterima sendiri, ialah bahwa Kristus telah mati karena dosa-dosa kita, sesuai dengan Kitab Suci, bahwa Ia telah dikuburkan, dan bahwa Ia telah dibangkitkan, pada hari yang ketiga, sesuai dengan Kitab Suci; bahwa Ia telah menampakkan diri kepada Kefas dan kemudian kepada kedua belas murid-Nya. Sesudah itu Ia menampakkan diri kepada lebih dari lima ratus saudara sekaligus; kebanyakan dari mereka masih hidup sampai sekarang, tetapi beberapa di antaranya telah meninggal. Selanjutnya Ia menampakkan diri kepada Yakobus, kemudian kepada semua rasul. Dan yang paling akhir dari semuanya Ia menampakkan diri juga kepadaku."Namun, ada beberapa

\footnotetext{
${ }^{12}$ Billy Mathias, Ensiklopedia Alkitab Praktis (Bandung: Lembaga Literatur Baptis, 1994), 64.

${ }^{13}$ Norman Geisler, Ketika Alkitab Dipertanyakan (Yogyakarta: Andi, 2006), 142.
} 
kemungkinan bahwa Yesus tidak benarbenar bangkit:

Yusuf dari Arimatea, pemilik kubur, mencuri mayat-Nya. Sanggahan: Yusuf adalah seorang Yahudi yang saleh dan tidak mau melanggar hari Sabat, terutama hariPaskah (Luk. 23:50-56). Lagi pula, setelah kematian Yesus, ada sepasukan tentara Romawi yang menjaga makam Yesus. ${ }^{14}$ Mereka tidak akan mau menerima suap untuk membiarkan orang Yahudi membuka meterai dan memindahkan mayat. Jadi, Yusuf dari Arimatea tidak mungkin mencuri tubuh Yesus. Ini juga berlaku untuk Nikodemus maupun murid-murid Yesus lain. ${ }^{15}$

\section{Penguasa Romawi atau Pemuka Agama}

Yahudi Mengambil Tubuh Yesus

Sanggahan: Para penguasa tersebut sangat menentang kehadiran Yesus, apalagi mereka mengetahui pemberitahuan Yesus bahwa Ia akan bangkit. Hilangnya mayat malah akan menimbulkan kesan nubuat Yesus itu benar terjadi. Lagi pula, jika mayat itu ada pada mereka, mereka hanya perlu menunjukkannya kepada masyarakat umum untuk membuktikan bahwa Yesus tidak bangkit. Jadi, penguasa Romawi maupun pemuka agama Yahudi tidak mungkin mencuri tubuh Yesus. ${ }^{16}$

\section{Perempuan-perempuan Pergi ke Kubur yang} Salah

Sanggahan: Para perempuan itu mengikuti penguburan dan tinggal beberapa lama di kubur saat orang-orang lain sudah pergi. Maria Magdalena paling sedikit 2 kali

\footnotetext{
${ }^{14}$ Ibid.

${ }^{15}$ John Drane, Memahami Perjanjian Baru: Pengantar Historis-Teologis (Jakarta: BPK Gunung Mulia, 1996), 146-147.

${ }^{16}$ Norman Geisler, Ketika Alkitab Dipertanyakan, 142.
}

pulang pergi ke kubur. Petrus dan Yohanes berlari mendahului Maria Magdalena ke kubur yang sama tanpa diantar oleh para perempuan itu. Jadi, tidak mungkin mereka semua mengunjungi kubur yang salah. ${ }^{17}$

\section{Kebangkitan Kristen menurut Rasul Paulus}

Rasul Paulus merupakan sosok pribadi yang sangat mengagumkan sekaligus menarik untuk menjadi kajian studi yang tidak berkesudahan. Betapa tidak, sebelum menjadi rasul ia mengaku diri sebagai seorang Farisi (Fil. 3:5) yang "jauh lebih maju" di antara teman sebayanya dalam hal agama Yahudi.

Beker menuangkan hasil studinya dalam rangka menemukan "pusat teologi" rasul Paulus dalam sebuah buku berjudul Paul the Apostle: The Triumph of God in Life and Thought. ${ }^{18}$ Dalam buku ini, Beker memberikan argumentasinya bahwa teologi rasul Paulus merupakan hasil dari sebuah interaksi kritis antara "the coherent center of the Gospel" dengan "the contingent particularity of the problems" yang senantiasa rasul Paulus jumpai dalam tugas pelayanannya. Menurut Beker, keberhasilan rasul Paulus dalam melaksanakan tugas dan tanggung jawab ini ditentukan oleh kemampuan hermeneutisnya yang tidak hanya "distils a specific core out of the variety of Gospel tradition in the early Church but also incarnates that core into the particularity of historical occasions and contexts". Melalui proses hermeneutis inilah rasul Paulus berhasil menarik keluar aspek universal Injil, untuk selanjutnya diterapkan secara kreatif dalam situasi-situasi khusus,

${ }^{18}$ J.C. Beker, Paul the Apostle: The Triumph of God in Life and Thought (Edinburgh:T. \& T. Clark, 1980), 97.
} 
sesuai dengan tuntutan pelayanannya. Menurut Beker, cara inilah yang mengakibatkan rasul Paulus sanggup mengkomunikasikan Injilnya secara baru dan segar dalam setiap situasi pelayanan yang ia hadapi. Studi intensif ini telah mendorong sekelompok ahli teologi Paulus untuk sekali lagi mendiskusikan "pusat teologi" rasul Paulus tersebut. ${ }^{19}$

Rasul Paulus dalam suratnya kepada jemaat di Roma mengatakan bahwa Kristus yang telah mati, bahkan bangkit dari antara orang mati menjadi pembela kita (orang percaya). Rasul Paulus secara jelas dan mendetail menjelaskan tentang kebangkitan Yesus Kristus kepada seluruh jemaat agar jemaat tidak mudah dipengaruhi oleh filsafat orang Yunani yang tidak percaya adanya kebangkitan dan juga ajaran-ajaran yang lain. Selain Rasul Paulus menjelaskan lewat pengajarannya, ia rela menderita dan dianiaya karena keyakinannya terhadap kebangkitan Yesus. Melalui pelayanan Rasul Paulus dengan berita kebangkitan Yesus maka berdirilah jemaat-jemaat baru baik di Asia maupun Eropa. Menurut rasul Paulus Bapa aktif dalam karya pendamaian dan kebangkitan secara khusus berasal dari Allah (Rm. 4:24; 8:11; 10:9). Bagi Paulus, peristiwa kematian Yesus menghasilkan pendamaian dan kebangkitan sebagai buah kasih Allah yang mendatangkan keselamatan bagi manusia. $^{20}$

Surat Paulus pada jemaat di Korintus (1Kor. 15:20), pada kata "dibangkitkan" menggunakan kata kerja yang sama dengan yang digunakan pada ayat 12 , yaitu kata

\footnotetext{
${ }^{19}$ Y. Tridarmanto,(2008), "Melacak Kembali Metodologi Rasul Paulus dalam berteologi”, Gema Teologi, 32(2), 2-3. http://journaltheo.ukdw.ac.id/index.php/gema/article/view/43.

${ }^{20}$ A. Susanti, (2019), "Keselamatan dalam Konsep Rasul Paulus", Integritas: Jurnal Teologi, 1(1), 15-28.
}

egegertai dalam bentuk perfect, indikatif, pasif, orang ketiga tunggal. Berarti (Dia) Kristus dibangkitkan oleh Allah sendiri dan kebangkitan-Nya itu memiliki pengaruh atau dampak bagi orang percaya baik masa sekarang maupun masa yang akan datang. Walaupun Kristus mengalami kematian tubuh, namun telah dibangkitkan dari antara orang-orang yang sudah mati. Jadi, Kristus sebagai yang sulung atau yang pertama mewakili semua orang percaya yang akan dibangkitkan. Sebab, melalui kebangkitan Kristus dari antara orang mati, memberikan pengharapan serta jaminan bagi umat-Nya. Kristus terlebih dahulu dibangkitkan dan kemudian orang-orang percaya pada masa yang akan datang. ${ }^{21}$

\section{Kebangkitan Kristus menurut Surat - Surat Misi Paulus}

Paulus hanya sekali menyebut Yesus sebagai "Adam yang akhir" (1 Kor. 15:45). Namun, dia memang mengkontraskan Kristus dan Adam beberapa kali dalam kitab Roma dan 1 Korintus.pada saat dia menggambarkan Yesus sebagai "Adam yang akhir" dalam Korintus, kata sifat "akhir" menekankan perbedaan antara kedua orang itu. Paulus memandang Adam sebagai orang yang ketidaktaatannya membawa dosa dan maut bagi semua orang (Rm. 5:12; 1 Kor. 15:21-22). Sebaliknya, ketaatan Kristus, membawa hidup dan janji kebangkitan serta hidup kekal bagi semua orang yang memiliki hubungan dengan-Nya (Rm. 5:17; 1 Kor.

\footnotetext{
${ }^{21}$ N. Rande \& D. Ronda, (2013), "Makna Kebangkitan Kristus berdasarkan I Korintus 15:12-28 dan Implikasinya bagi Orang Percaya", Jurnal Jaffray, 11(2), 1-28. https://doi.org/10.25278/jj71.v11i2.79.
} 
15:21-22). Fokus pembahasan dalam 1 Korintus 15 adalah kebangkitan (ay.12). ${ }^{22}$

Bagi Paulus, kebangkitan Kristus merupakan peneguhan Allah bahwa kematian Yesus memang membayar hukuman dosa. Itulah yang dia katakan kepada jemaat Korintus (1 Kor. 15:17). Makna yang sama terdapat dalam Roma 4:25. Kebangkitan itu menyatakan kebenaran bahwa kematian Kristus memungkinkan adanya pembebasan dari hukuman dosa, selamat dari kuasa dosa, dan kebebasan akhir dari keberadaan dosa. Kebangkitan Yesus juga mengawali peranan-Nya sebagai Tuhan. Paulus berbicara tentang hal ini ketika berada di Roma (Rm. 1:4). Sebuah ekspresi otoritas ini ialah pelayanan syafaat Yesus demi umat Kristen, suatu alasan yang bisa Paulus nyatakan dengan yakin bahwa "Demikianlah sekarang tidak ada penghukuman bagi mereka yang ada didalam Kristus Yesus" (Rm. 8:1).

Paulus juga menganggap kebangkitan Kristus sebagai sesuatu yang akan dialami oleh orang Kristen. "Kristus telah dibangkitkan dari antara orang mati, sebagai yang sulung dari orang - orang yang telah meninggal" (1 Kor. 15:20). Dalam makna yang sama, dia menulis kepada jemaat di Roma (Rm. 8:11). Maka kebangkitan lebih banyak merupakan karya Allah dan Roh Kudus daripada karya Kristus. Namun, Paulus memandang kebangkitan secara integral dengan pelayanan Yesus sekarang dan merupakan aspek penting dari pengalaman masa depan orang Kristen. ${ }^{23}$

Persatuan orang percaya dengan Kristus adalah doktrin yang merupakan pemikiran kunci dalam ajaran Tuhan bahkan

${ }^{22}$ R.B. Zuck, A Biblical Theology of the New Testament (Chicago: Moody Publishers. 1994), 291292.

\footnotetext{
${ }^{23}$ Ibid., 312.
}

sangat penting bagi teologi Paulus sehingga seorang penafsir, James S. Stewart menyebutnya sebagai "inti dari agama Paulus," sebagaimana dikutip oleh Boice dalam bukunya yaitu Dasar-Dasar Iman Kristen. $^{24}$ Bagi Paulus, persatuan dengan Kristus bisa berarti orang percaya berada di dalam Kristus dan Kristus berada di dalam diri orang percaya. "Jadi siapa yang ada di dalam Kristus ia adalah ciptaan baru: yang lama sudah berlalu, sesungguhnya yang baru sudah datang" (2 Kor. 5:17) dan "Aku telah disalibkan dengan Kristus; namun aku hidup, tetapi bukan lagi aku sendiri yang hidup, melainkan Kristus yang hidup di dalam aku. Dan hidupku yang kuhidupi sekarang di dalam daging, adalah hidup oleh iman dalam Anak Allah yang telah mengasihi aku dan menyerahkan diri-Nya untuk Aku" (Gal. 2:19-20). Ini adalah ekspresi dari kedekatan Tuhan dengan orang percaya yang merupakan salah satu dari "misteri-misteri" besar yang telah dinyatakan dalam Injil dan diberitahukan oleh Allah hanya melalui penyataan (wahyu). ${ }^{25}$

Salah satu pikiran Paulus tentang persatuan dengan Kristus tertuang dalam suratnya kepada jemaat di Roma. Melalui Roma 6:1-14, Paulus menjelaskan konsep pemikirannya tentang persatuan orang percaya dengan kematian dan kebangkitan Kristus. Paulus menguraikannya sebagai dasar dari pernyataannya, "Kita telah mati bagi dosa" (Rm. 6:2). Karena orang percaya telah mati bagi dosa, maka ia tidak boleh hidup bertekun di dalam dosa. Paulus harus menjelaskan hal ini karena selalu ada interpretasi yang salah terhadap

\footnotetext{
${ }^{24}$ J. Montgomery Boice, Dasar-Dasar Iman Kristen (Surabaya: Momentum, 2011), 441.

${ }^{25}$ Irwan Tjulianto, Kehidupan Kristen: Sebuah pengantar doktrinal (Surabaya: Momentum, 2017), 238.
} 
pengajarannya tentang pembenaran sebagai anugerah Allah secara cuma-cuma yang dapat diterima hanya oleh iman, bukan berdasarkan perbuatan manusia. Secara khusus juga terhadap pernyataannya di akhir Roma pasal 5 bahwa di mana dosa bertambah banyak di situ kasih karunia Allah berlimpah-limpah (Rm. 5:20-21). Seseorang mungkin berkata, "Jika pembenaran tidak berdasarkan perbuatan manusia dan kasih karunia Allah akan berlimpah-limpah ketika dosa bertambah banyak, maka baiklah kita terus berbuat dosa agar kasih karunia Allah semakin berlimpah." Sebelum menulis surat kepada jemaat di Roma, rasul Paulus dalam pelayanannya pernah menghadapi hal ini. Jemaat Korintus hidup dalam moralitas yang sangat longgar. Paulus menyikapinya dengan memperingatkan mereka bahwa mereka telah dipersatukan dengan Kristus, bukan hanya dari segi roh mereka, melainkan seluruh keberadaan mereka. Paulus menegaskan, "Tidak tahukah kamu, bahwa tubuhmu adalah anggota Kristus?" (1 Kor. 6:15). Karena itu, orang percaya harus meninggalkan dosa dan hidup menurut keadaan mereka yang baru yang telah dipersatukan dengan Kristus. Ladd menyatakan bahwa karena adanya faktafakta penebusan tertentu, maka ada pula akibat-akibat tertentu yang tak dapat dihindari. Aku telah dipersatukan dengan Kristus, karena itu aku harus hidup menurut cara tertentu. $^{26}$ Kepada jemaat di Galatia, Paulus juga menegaskan bahwa orang percaya telah mengenakan Kristus (Gal. 3:27) dan telah dimerdekakan oleh Kristus (Gal. 5:1). Tetapi kemerdekaan itu jangan dipakai sebagai kesempatan untuk kehidupan dalam dosa, melainkan untuk melayani oleh kasih (Gal. 5:13).

${ }^{26}$ G. Eldon Ladd, Teologi Perjanjian Baru Jilid 2 (Bandung: Kalam Hidup, 1999), 297.
Rasul Paulus dalam suratnya kepada Jemaat di Roma mengatakan bahwa Kristus yang telah mati, bahkan bangkit dari antara orang mati menjadi pembela kita (orang percaya). Karena itu, siapakah yang akan memisahkan kita dari kasih Kristus? Penindasan, kesesakan, penganiayaan, kelaparan, ketelanjangan, bahaya, atau pedang, hal itu tak dapat memisahkan kita dari kasih Kristus yang telah bangkit. Rasul Paulus secara jelas dan mendetail menjelaskan tentang kebangkitan Yesus Kristus kepada seluruh jemaat agar jemaat tidak mudah dipengaruhi oleh filasafat orang Yunani yang tidak percaya adanya kebangkitan dan juga ajaran-ajaran yang lain. Selain Rasul Paulus menjelaskan lewat pengajarannya, ia rela menderita dan dianiaya karena keyakinannya terhadap kebangkitan Yesus. Melalui pelayanan Rasul Paulus dengan berita kebangkitan Yesus maka berdirilah jemaat-jemaat baru baik diAsia maupun di Eropa. ${ }^{27}$

Bila Kristus tidak bangkit, maka tidak ada kebangkitan orang beriman dan tidak ada jaminan kemenangan atas dosa (Milard J. Berquist, 48). Jelaslah kita ketahui bahwa iman Kristen didirikan di atas dasar orang yang bangkit atau hidup, bukan di atas orang yang mati. Orang Kristen yang menyadaritugasnya sebagai murid Kristus, pasti rajin dan giat di dalam memberitakan kebangkitan Yesus. Dengan adanya kebangkitan Kristus berarti iman Kristen mempunyai arti yang besar dan memberi pengharapan kepada pengikutnya bahwa mereka pun akan dibangkitkan juga. Kalau Kristus tidak dibangkitkan maka kekristenan itu hanya suatu benda museum yang menarik, papar Paul E. Little. Berikut, pernyataaan Canon West Coot yang dikutip

${ }^{27}$ A. M. Hunter, Memperkenalkan Theologia Perjanjian Baru, 71-72. 
oleh Paul E. Litile, bahwa sesungguhnya, kalau kita pertimbangkan semua fakta yang ada, maka tidak terlalu berlebih-lebihan untuk dikatakan bahwa tidak ada peristiwa sejarah yang lebih baik atau lebih banyak buktinya dari pada kebangkitan Kristus. Tidak ada orang yang akan mengatakan kurangnya bukti-bukti kebangkitan Yesus dari antara orang mati, kecuali mereka yang sudah sejak semula mempunyai praduga bahwa bukti-bukti itu palsu. ${ }^{28}$

J.R.W. Stott mengutip pernyataan seorang ahli sebagai berikut bahwa: sebagai seorang ahli hukum saya telah mengadakan penyelidikan yang seksama tentang pembuktian hari paskah yang pertama itu. Bagi saya buktinya tegas, pembuktian dalam Injil mempunyai sifat jujur ini dan sebagai ahli hukum saya menerima sebulatbulat hati saya pengakuan ini sebagai kesaksian orang- orang yang telah sanggup membuktikannya. ${ }^{29}$

Kebangkitan Kristus berarti la leblh kuat dari pada maut dan berarti pekerjaannya sungguh telah selesai. Kebangkitan Yesus Kristus berarti la mencapai segala kemenangan, juga atas mati dan dosa. Kebangkitan Yesus Kristus menunjukkan Keallahan-Nya, sebab tidak ada orang yang menang atas maut.

\section{Kebangkitan Kristus menurut Surat - Surat Misi Paulus}

Paulus hanya sekali menyebut Yesus sebagai "Adam yang akhir" (1 Kor. 15:45). Namun, dia memang mengkontraskan Kristus dan Adam beberapa kali dalam kitab Roma dan 1 Korintus.pada saat dia menggambarkan Yesus sebagai "Adam yang

\footnotetext{
${ }^{28}$ P. E. Little, Akal dan Kekristenan (Bandung: Kalam Hidup, 1979), 37.

${ }^{29}$ J. R. W. Stott, Karya Kristus bagi Kita (Jakarta: BPK Gunung Mulia, 1967), 39.
}

akhir" dalam Korintus, kata sifat "akhir" menekankan perbedaan antara kedua orang itu. Paulus memandang Adam sebagai orang yang ketidaktaatannya membawa dosa dan maut bagi semua orang (Rm. 5:12; 1 Kor. 15:21-22). Sebaliknya, ketaatan Kristus, membawa hidup dan janji kebangkitan serta hidup kekal bagi semua orang yang memiliki hubungan dengan-Nya (Rm. 5:17; 1 Kor. 15:21-22). Fokus pembahasan dalam 1 Korintus 15 adalah kebangkitan (ay.12). ${ }^{30}$

Bagi Paulus, kebangkitan Kristus merupakan peneguhan Allah bahwa kematian Yesus memang membayar hukuman dosa. Itulah yang dia katakan kepada jemaat Korintus (1 Kor. 15:17). Makna yang sama terdapat dalam Roma 4:25. Kebangkitan itu menyatakan kebenaran bahwa kematian Kristus memungkinkan adanya pembebasan dari hukuman dosa, selamat dari kuasa dosa, dan kebebasan akhir dari keberadaan dosa. Kebangkitan Yesus juga mengawali peranan-Nya sebagai Tuhan. Paulus berbicara tentang hal ini ketika berada di Roma (Rm. 1:4). Sebuah ekspresi otoritas ini ialah pelayanan syafaat Yesus demi umat Kristen, suatu alasan yang bisa Paulus nyatakan dengan yakin bahwa "Demikianlah sekarang tidak ada penghukuman bagi mereka yang ada didalam Kristus Yesus" (Rm. 8:1).

Paulus juga menganggap kebangkitan Kristus sebagai sesuatu yang akan dialami oleh orang Kristen. "Kristus telah dibangkitkan dari antara orang mati, sebagai yang sulung dari orang - orang yang telah meninggal" (1 Kor. 15:20). Dalam makna yang sama, dia menulis kepada jemaat di Roma (Rm. 8:11). Maka kebangkitan lebih banyak merupakan karya Allah dan Roh Kudus daripada karya Kristus. Namun,

\footnotetext{
${ }^{30}$ R.B. Zuck, A Biblical Theology of the
} New Testament, 291-292. 
Paulus memandang kebangkitan secara integral dengan pelayanan Yesus sekarang dan merupakan aspek penting dari pengalaman masa depan orang Kristen. ${ }^{31}$

Persatuan orang percaya dengan Kristus adalah doktrin yang merupakan pemikiran kunci dalam ajaran Tuhan bahkan sangat penting bagi teologi Paulus sehingga seorang penafsir, Stewart menyebutnya sebagai "inti dari agama Paulus," sebagaimana dikutip oleh Boice dalam bukunya yaitu Dasar-Dasar Iman Kristen. ${ }^{32}$ Bagi Paulus, persatuan dengan Kristus bisa berarti orang percaya berada di dalam Kristus dan Kristus berada di dalam diri orang percaya. "Jadi siapa yang ada di dalam Kristus ia adalah ciptaan baru: yang lama sudah berlalu, sesungguhnya yang baru sudah datang" (2 Kor. 5:17) dan "Aku telah disalibkan dengan Kristus; namun aku hidup, tetapi bukan lagi aku sendiri yang hidup, melainkan Kristus yang hidup di dalam aku. Dan hidupku yang kuhidupi sekarang di dalam daging, adalah hidup oleh iman dalam Anak Allah yang telah mengasihi aku dan menyerahkan diri-Nya untuk Aku" (Gal. 2:19-20). Ini adalah ekspresi dari kedekatan Tuhan dengan orang percaya yang merupakan salah satu dari "misteri-misteri" besar yang telah dinyatakan dalam Injil dan diberitahukan oleh Allah hanya melalui penyataan (wahyu). ${ }^{33}$

Salah satu pikiran Paulus tentang persatuan dengan Kristus tertuang dalam suratnya kepada jemaat di Roma. Melalui Roma 6:1-14, Paulus menjelaskan konsep pemikirannya tentang persatuan orang percaya dengan kematian dan kebangkitan

\footnotetext{
${ }^{31}$ Ibid., 312.

${ }^{32}$ J. Montgomery Boice, Dasar-Dasar Iman Kristen (Surabaya: Momentum, 2011), 441.

${ }^{33}$ Irwan Tjulianto, Kehidupan Kristen: Sebuah Pengantar Doktrinal (Surabaya: Momentum, 2017), 138.
}

Kristus. Paulus menguraikannya sebagai dasar dari pernyataannya, "Kita telah mati bagi dosa" (Rm. 6:2). Karena orang percaya telah mati bagi dosa, maka ia tidak boleh hidup bertekun di dalam dosa. Paulus harus menjelaskan hal ini karena selalu ada interpretasi yang salah terhadap pengajarannya tentang pembenaran sebagai anugerah Allah secara cuma-cuma yang dapat diterima hanya oleh iman, bukan berdasarkan perbuatan manusia. Secara khusus juga terhadap pernyataannya di akhir Roma pasal 5 bahwa di mana dosa bertambah banyak di situ kasih karunia Allah berlimpah-limpah (Rm. 5:20-21). Seseorang mungkin berkata, "Jika pembenaran tidak berdasarkan perbuatan manusia dan kasih karunia Allah akan berlimpah-limpah ketika dosa bertambah banyak, maka baiklah kita terus berbuat dosa agar kasih karunia Allah semakin berlimpah." Sebelum menulis surat kepada jemaat di Roma, rasul Paulus dalam pelayanannya pernah menghadapi hal ini. Jemaat Korintus hidup dalam moralitas yang sangat longgar. Paulus menyikapinya dengan memperingatkan mereka bahwa mereka telah dipersatukan dengan Kristus, bukan hanya dari segi roh mereka, melainkan seluruh keberadaan mereka. ${ }^{34}$ Paulus menegaskan, "Tidak tahukah kamu, bahwa tubuhmu adalah anggota Kristus?" (1 Kor. 6:15). Karena itu, orang percaya harus meninggalkan dosa dan hidup menurut keadaan mereka yang baru yang telah dipersatukan dengan Kristus. Ladd menyatakan bahwa karena adanya faktafakta penebusan tertentu, maka ada pula akibat-akibat tertentu yang tak dapat dihindari. Aku telah dipersatukan dengan Kristus, karena itu aku harus hidup menurut

${ }^{34}$ G. Eldon Ladd, Teologi Perjanjian Baru Jilid 2 (Bandung: Kalam Hidup, 1999), 297. 
cara tertentu. ${ }^{35}$ Kepada jemaat di Galatia, Paulus juga menegaskan bahwa orang percaya telah mengenakan Kristus (Gal. 3:27) dan telah dimerdekakan oleh Kristus (Gal. 5:1). Tetapi kemerdekaan itu jangan dipakai sebagai kesempatan untuk kehidupan dalam dosa, melainkan untuk melayani oleh kasih (Gal. 5:13).

Rasul Paulus dalam suratnya kepada Jemaat di Roma mengatakan bahwa Kristus yang telah mati, bahkan bangkit dari antara orang mati menjadi pembela manusia (orang percaya). Karena itu, siapakah yang akan memisahkan kita dari kasih Kristus? Penindasan, kesesakan, penganiayaan, kelaparan, ketelanjangan, bahaya, atau pedang, hal itu tak dapat memisahkan manusia dari kasih Kristus yang telah bangkit. Rasul Paulus secara jelas dan mendetail menjelaskan tentang kebangkitan Yesus Kristus kepada seluruh jemaat agar jemaat tidak mudah dipengaruhi oleh filasafat orang Yunani yang tidak percaya adanya kebangkitan dan juga ajaran-ajaran yang lain. Selain Rasul Paulus menjelaskan lewat pengajarannya, ia rela menderita dan dianiaya karena keyakinannya terhadap kebangkitan Yesus. Melalui pelayanan Rasul Paulus dengan berita kebangkitan Yesus maka berdirilah jemaat-jemaat baru baik diAsia maupun di Eropa. ${ }^{36}$

Bila Kristus tidak bangkit, maka tidak ada kebangkitan orang beriman dan tidak ada jaminan kemenangan atas dosa. ${ }^{37}$ Jelaslah kita ketahui bahwa iman Kristen didirikan di atas dasar orang yang bangkit atau hidup, bukan di atas orang yang mati. Orang Kristen yang menyadaritugasnya

\footnotetext{
${ }^{35}$ Ibid., 297.

${ }^{36}$ A. M. Hunter, Memperkenalkan Theologia Perjanjian Baru,71-72.

${ }^{37}$ Millard J. Berguist, Penyelidikan Surat Kristus yang Perjanjian Lama (Bandung: Lembaga Literature Baptis, t.p.), 48.
}

sebagai murid Kristus, pasti rajin dan giat di dalam memberitakan kebangkitan Yesus. Dengan adanya kebangkitan Kristus berarti iman Kristen mempunyai arti yang besar dan memberi pengharapan kepada pengikutnya bahwa mereka pun akan dibangkitkan juga. Kalau Kristus tidak dibangkitkan maka kekristenan itu hanya suatu benda museum yang menarik, papar Little. Berikut, pernyataaan Canon West Coot yang dikutip oleh Paul E. Litile, bahwa sesungguhnya, kalau kita pertimbangkan semua fakta yang ada, maka tidak terlalu berlebih-lebihan untuk dikatakan bahwa tidak ada peristiwa sejarah yang lebih baik atau lebih banyak buktinya dari pada kebangkitan Kristus. Tidak ada orang yang akan mengatakan kurangnya bukti-bukti kebangkitan Yesus dari antara orang mati, kecuali mereka yang sudah sejak semula mempunyai praduga bahwa buktibukti itu palsu. ${ }^{38}$

Stott mengutip pernyataan seorang ahli sebagai berikut bahwa: sebagai seorang ahli hukum saya telah mengadakan penyelidikan yang seksama tentang pembuktian hari paskah yang pertama itu. Bagi saya buktinya tegas, pembuktian dalam lnjil mempunyai sifat jujur ini dan sebagai ahli hukum saya menerima sebulatbulat hati saya pengakuan ini sebagai kesaksian orang- orang yang telah sanggup membuktikannya. ${ }^{39}$

Kebangkitan Kristus berarti la leblh kuat dari pada maut dan berarti pekerjaannya sungguh telah selesai. Kebangkitan Yesus Kristus berarti la mencapai segala kemenangan, juga atas mati dan dosa. Kebangkitan Yesus Kristus

\footnotetext{
${ }^{38}$ Paul E. Little, Akal dan Kekristenan (Bandung: Kalam Hidup, 1979), 37.

${ }^{39}$ J. R. W. Stott, Karya Kristus bagi Kita, 39.
} 
menunjukkan Keallahan-Nya, sebab tidak ada orang yang menang atas maut. ${ }^{40}$

Paulus menulis surat-surat ini saat dia berada di dalam tahanan yang pertama kali di Roma. Paulus menulis surat-surat kepada jemaat Filipi terutama untuk mengutarakan rasa syukur dan kasih sayangnya untuk para Orang Suci Filipi (Flp. 1:1) dan untuk menghibur hati mereka dari kekecewaan akan penahanannya yang lama. Paulus menulis surat kepada jemaat Kolose sebagai akibat dari laporan bahwa para Orang Suci Kolose sedang jatuh ke dalam kekhilafan yang serius. Mereka percaya bahwa kesempurnaan datang melalui ketaatan yang saksama terhadap tata cara-tata cara lahiriah saja daripada pengembangan karakter seperti Kristus. $^{41}$

Surat kepada jemaat Efesus mempunyai kepentingan besar, karena memuat ajaran-ajaran Paulus tentang Gereja Kristus. Surat kepada Filemon adalah sepucuk surat pribadi tentang Onesimus, budak yang telah merampok majikannya, Filemon, dan melarikan diri ke Roma. Paulus mengutus Onesimus kembali kepada majikannya dengan surat yang meminta agar Onesimus diampuni. Onesimus adalah nama laki-laki yang dalam bahasa Yunani berarti berguna. Dia adalah seorang budak yang melarikan diri dari rumah tuannya yaitu Filemon yang tinggal di kota Kolose, menurut catatan dalam Perjanjian Baru. Onesimus kemudian tertangkap dan dipenjarakan bersama-sama Paulus. Ia mencari perlindungan kepada Paulus, yang kemudian mengirimkan Surat kepada Filemon agar memperlakukan Onesimus

\footnotetext{
${ }^{40}$ R. Soedarmo, Ikhtisar Dogmatika (Jakarta: BPK Gunung Mulia, 2002), 151-152.

${ }^{41}$ R. B. Zuck, A Biblical Theology of the New Testament, 292.
}

dengan baik. ${ }^{42}$ Paulus menulis surat kepada orang-orang Ibrani bagi para anggota Gereja orang Yahudi untuk membujuk mereka bahwa hukum Musa telah digenapi di dalam Kristus dan bahwa hukum Injil Kristus telah menggantikannya. ${ }^{43}$

Allah yang bekerja dan menyelamatkan. Allah berkehendak untuk bekerja melalui upaya mediasi Anak-Nya, yang dijadikan dalam rupa-Nya dan didalam Dia seluruh kepenuhan ilahi berdiam (Kol. 1:15, 19; 2:9). Sebenarnya, keinginan Allah ialah agar Anak berkuasa didalam segala sesuatu, sebagaimana terlihat dalam karya Anak dalam penciptaan dan penebusan (dibuktikan khususnya melalui kebangkitanNya; Kol. 1:15-20). Kata kerja masa lampau dalam Kolose 1:13 menunjukkan bahwa pemindahan(Pemindahan Dimaksudkan Bawa Pada Saat Allah Bertindak Untuk Melepaskan Umat Manusia Keluar Dari Cengkeram Setan Dan Menempatkan Manusia Dalam Hubungan Pribadi Dengan Kristus Dan Pemerintahan-Nya (Kol. 1:1314)., n.d.) ini telah terjadi, meski implikasinya menjangkau ke masa depan untuk hal - hal yang belum terjadi (errysato, "Dia membebaskan", Kol. 3:3-4). ${ }^{44}$

Kehidupan orang percaya disamakan dengan Yesus sehingga Paulus menulis tentang kematian bersama Kristus atas roh roh yang menguasai dunia dan dibangkitkan bersama-Nya (Kol. 2:20 - 3:11). Kata - kata ini mengulangi kiasan dalam Kolose 2:9-15. Kata-kata tersebut menyiratkan perubahan

${ }^{42}$ W.R.F. Browning, Kamus Alkitab: A Dictionary of the Bible (Jakarta: BPK Gunung Mulia, 2008), 296.

${ }^{43}$ Surat-Surat Paulus. (n.d.). Retrieved April
2020,
18,
https://www.churchofjesuschrist.org/study/scriptures/
gs/pauline-epistles?lang=ind.
${ }^{44}$ W.R.F. Browning, Kamus Alkitab: A
Dictionary of the Bible, 343-344.
Dictionary of the Bible, 343-344. 
identitas dan komitmen, sehingga standar, metode, dan kekuatan makhluk dunia tidak lagi menentukan hidup. Sebaliknya, Allah yang menyelamatkan mereka dalam Kristus, memimpin dan menentukkannya. Jadi berpikir surgawi bukanlah melarikan atau menarik diri, tetapi mencerminkan karakteristik - karakteristik ilahi dari hidup baru yang Allah berikan kepada orang percaya melalui kebangkitan-Nya (Kol. 3:117). ${ }^{45}$

Bagian sebelumnya mengakhiri deng an kuasa Allah yang bekerja di dalam orang kudus, yaitu jemaat Allah. dan justru kuasa ini yang di perdalam kemudian. Yang pertama, kuasa kebangkitan Kristus. Kita melihat bahwa apa yang penting untuk Paulus dalam doanya, hal itulah apa yang Allah kerjakan. Kita mau memfokuskan kepada doa tersebut. Karena kita melihat bahwa walaupun Paulus berdoa untuk orang lain, doa Paulus berisi kemuliaan Allah. tetapi tidak hanya dalam kata-kata yang bersifat umum. Ada sebabnya Paulus mau meninggikan Allah, yaitu karena kebangkitan Kristus, kuasa dan kedudukan Kristus dan bagaimana Kristus adalah yang mempersatukan jemaat-Nya sebagai kepalaNya. Dari Efesus 1:21-22 kita melihat kemuliaan Kristus yang diatas segala sesuatu, tidak hanya di dunia ini (bdgkan Luk. 4:6-8) tetapi di dalam dunia yang akan datang. Itu kedudukan Allah sendiri. ${ }^{46}$

\section{Kebangkitan Kristus menurut Surat- surat Pengembalaan Paulus}

Paulus menulis surat-surat ini setelah dia dibebaskan dari tahanan di Roma yang

\footnotetext{
${ }^{45}$ Ibid., 346.

46،'Introduksi surat penjara, Scribd. Retrieved April 18, 2020, from https://id.scribd.com/doc/26300610/introduksi-suratpenjara.
}

pertama kali. Paulus melakukan perjalanan ke Efesus, di mana dia meninggalkan Timotius untuk menghentikan pertumbuhan beberapa bentuk spekulasi, bermaksud sesudahnya untuk kembali. Dia menulis surat pertamanya kepada Timotius, barangkali dari Makedonia, untuk menasihati dan mendorongnya dalam pemenuhan kewajibannya. Paulus menulis surat kepada Titus pada suatu masa ketika dia bebas dari tahanan. Dia mungkin telah mengunjungi Kreta, di mana Titus sedang melayani. Surat ini terutama berurusan dengan kehidupan yang saleh dan disiplin di dalam Gereja.

Nama "Kristus Yesus" muncul dalam 25 dari 32 referensi untuk Kristus dalam surat - surat pengembalaan, sehingga surat surat ini menyajikan suatu Kristologi yang dimuliakan dimana peranan-Nya sebagai Mesias ditekankan. Dialah Tuhan (kyrios, 1 Tim. 1:2, 12; 6:3, 14; 2 Tim. 1:2), suatu gelar yang juga mengekpresikan konsep kemuliaan. Istilah ini khususnya berguna bagi Paulus. Sementara keselamatan dikehendaki Bapa, hal itu disediakan oleh Kristus. Bahwa "Kristus Yesus datang kedunia untuk menyelamatkan orang berdosa" merupakan penegasan penting oleh Paulus (1 Tim. 1:15). Paulus lebih empatik dalam surat Titus pada saat menyebut Kristus "Yesus, Juruselamat kita" (Tit. 1:4) dan "Allah yang Mahabesar dan Juruselamat kita Yesus Kristus" (Tit. 2:13). ${ }^{47}$

Kebutuhan akan seseorang perantara menerima kejatuhan universal umat manusia dalam dosa sebagai suatu kenyataan. Tindakan harus datang dari seseorang yang berkenan bagi Allah dan bisa memenuhi kebutuhan manusia pada saat yang sama. Referensi untuk Kristus sebagai perantara berbicara lebih banyak tentang fungsi-Nya

${ }^{47}$ R. B. Zuck, A Biblical Theology of the New Testament, 393. 
ketimbang sebagai gelar tertentu. Terkandung dalam konsep seorang perantara ialah seorang yang "menegakkan suatu hubungan yang tidak pernah ada." 48 Sebagai perantara, Yesus, melalui kematian dan kebangkitan-Nya, menegakkan suatu hubungan baru antara Allah dan manusia. Semua yang memisahkan pencipta dan ciptaan-Nya disingkirkan didalam Kristus. Lea melihat dalam kata "perantara" suatu ketertkaitan dengan konsep perjanjian. ${ }^{49}$ Demikian juga surat Ibrani berisi tiga referensi untuk istilah ini yang berbicara tentang peranan Kristus dalam hubungannya dengan perjanjian baru (Ibr. 8:6; 9:15; 12:24). Berkenaan hubungan Kristus dan Allah dala teks dekat, Becker menyatakan, "kesatuan atau keesaan dari perantara bukan hanya meneguhkan kembali universalitas jalan keselamatan yang disiratkan oleh rumusan heis theos (satu Allah), tetapi juga menekankan jalan keselamatan satu-satunya adalah Kristus. $^{50}$

Penyempurnaan kerajaan bagi umat pilihan akan mengikuti penghakiman di akhir zaman (2 Tim. 2:12; bdg. 1 Tes. 2:12; 2 Tes. 1:4-5; Gal. 5:21; 1 Kor. 6:9-10; 15:50; Ef. 5:5). Kebangkitan Yesus menjamin dan membuat-Nya layak untuk tidak hanya menjadi hakim atas semua orang yang hidup dan mati, tetapi juga penguasa kerajaan-Nya. Ini mungkin juga berada dibalik keterkaitan antara status-Nya sebagai keturunan Daud dengan kebangkitan-Nya dalam 2 Timotius 2:8 (bdg. Kis. 13:33; 17:31; Ibr. 1:3; 10:12-

${ }^{48}$ G. Kittel, G. Friedrich \& G.W. Bromiley. (1985). Theological Dictionary of the New Testament: Abridged in One Volume (Grand Rapids: Wm. B. Eerdmans Publishing, 1985), 601.

${ }^{49}$ T. Lea \& H.P. Griffin. 1, 2 Timothy, Titus: An Exegetical and Theological Exposition of Holy Scripture (B \& H Publishing Group, 1992), 90.

${ }^{50}$ Zondervan, New International Dictionary of New Testament Theology 2 (USA: Zondervan Academic, 2003), 378.
13). Melalui kematian dan kebangkitan-Nya, tebusan bagi dosa telah dibayar, orang percaya telah ditebus, dan suatu yang hubungan diperdamaikan dengan Allah telah ditegakkan dengan janji akan kehidupan dan kekekalan akhir. Keselamatan yang diberikan dimasa lampau dapat dialami dalam kehidupan masa kini yang diubahkan sementara menantikan penyempurnaan masa depan. $^{51}$

\section{KESIMPULAN}

Kebangkitan tubuhnya dan berlanjut dalam kekekalan. Semuanya dapat terjadi karena Kristus, sesudah Ia bangkit dari antara orang mati, tidak mati lagi, dengan kata lain, Ia hidup dan terus hidup. Kebangkitan Kristus terjadi peralihan kekuasaan, Kristus beralih dari dikuasai oleh maut menjadi penguasa atas maut. Maut bukan hanya tidak berkuasa lagi atas Dia, tetapi justru oleh kebangkitan Kristus maut takluk di bawah kekuasaan Kristus.

Tanpa kebangkitan, iman Kristen tidak mungkin muncul. Murid-murid-Nya hanyalah simbol kekalahan dan kehancuran. Mungkin mereka akan mengingat Yesus sebagai guru terkasih mereka, dan penyaliban hanya akan melenyapkan harapan akan mesias. Salib akan kelihatan menyedihkan dan memalukan sebagai akhir karir Yesus. Tanpa kebangkitan, posisi Yesus sebagai Mesias dan Raja tidak akan terjelaskan. Tanpa kebangkitan, pencurahan Roh Kudus akan meninggalkan misteri yang tidak dapat dijelaskan. Tanpa kebangkitan, sumber kesaksian murid-murid hilang.

Dampak kebangkitan Yesus Kristus bagi kehidupan orang percaya adalah selama manusia ada di dalam Tuhan, apapun yang ia

\footnotetext{
${ }^{51}$ R. B. Zuck, A Biblical Theology of the New Testament, 397 .
} 
kerjakan, semua jerih payahnya dalam Tuhan, akan mendapat balasan atau upah dari Tuhan.

\section{DAFTAR PUSTAKA}

"Introduksi surat penjara, Scribd. Retrieved April 18, 2020, from https://id.scribd.com/doc/26300610/i ntroduksi-surat-penjara.

A.F. Lele \& R. Panggarra. (2015), "Makna Tujuh Ungkapan Yesus di Salib bagi Orang Percaya". Jurnal Jaffray, 13(2), 285-316. https://doi.org/10.25278/jj71.v13i2.1 81.

Beker, J.C. Paul the Apostle: The Triumph of God in Life and Thought. Edinburgh: T. \& T. Clark, 1980.

Berguist, Millard J. Penyelidikan Surat Kristus yang Perjanjian Lama. Bandung: Lembaga Literature Baptis, t.p.

Boice, J. Montgomery. Dasar-Dasar Iman Kristen. Surabaya: Momentum, 2011.

Browning, W.R.F. Kamus Alkitab: A Dictionary of the Bible. Jakarta: BPK Gunung Mulia, 2008.

Drane, John. Memahami Perjanjian Baru: Pengantar Historis-Teologis. Jakarta: BPK Gunung Mulia, 1996.

Frederik, H. (2015), “Konsep Persatuan dengan Kematian dan Kebangkitan Kristus berdasarkan Roma 6:1-14", Jurnal Jaffray, 13(2), 215-248. https://doi.org/10.25278/jj71.v13i2.1 79.

Geisler, Norman. Ketika Alkitab Dipertanyakan. Yogyakarta: Andi, 2006.

GP, Harianto. (2019), “ Mission in Suffering Context", Jurnal Excelsius Deo, 3(2).

Hunter, A. M. Memperkenalkan Theologia Perjanjian Baru. Jakarta: BPK Gunung Mulia, 1986.
Kittel, G., Friedrich, G., \& Bromiley, G.W. (1985). Theological Dictionary of the New Testament: Abridged in One Volume (Grand Rapids: Wm. B. Eerdmans Publishing, 1985), 601.

Ladd, G. Eldon.Teologi Perjanjian Baru Jilid 2 (Bandung: Kalam Hidup, 1999), 297.

Lea, T. \& Griffin, H.P. 1, 2 Timothy, Titus: An Exegetical and Theological Exposition of Holy Scripture. B \& H Publishing Group, 1992.

Little, Paul. E. Akal dan Kekristenan. Bandung: Kalam Hidup, 1979.

Mathias, Billy. Ensiklopedia Alkitab Praktis. Bandung: Lembaga Literatur Baptis, 1994.

Poerwadarminta, W.J.S. Kamus Umum Bahasa Indonesia. Jakarta: Balai Pustaka, 1984.

Rande, N. \& Ronda, D. (2013), "Makna Kebangkitan Kristus berdasarkan I Korintus 15:12-28 dan Implikasinya bagi Orang Percaya", Jurnal Jaffray, 11(2), $1-28$. https://doi.org/10.25278/jj71.v11i2.7 9.

Soedarmo, R. Ikhtisar Dogmatika. Jakarta: BPK Gunung Mulia, 2002.

Sutopo, H.B. Metodologi Penelitian Kuantitatif. Surakarta: Universitas Sebelas Maret Press, 2006.

Stott, J. R. W. Karya Kristus bagi Kita. Jakarta: BPK Gunung Mulia, 1967.

Surat-Surat Paulus. (n.d.). Retrieved April 18, 2020, from https://www.churchofjesuschrist.org/ study/scriptures/gs/paulineepistles?lang=ind.

Susanti, A. (2019). "Keselamatan dalam Konsep Rasul Paulus". Integritas: Jurnal Teologi, 1(1), 15-28.

Tjulianto, Irwan. Kehidupan Kristen: Sebuah Pengantar Doktrinal. Surabaya: Momentum, 2017. 
Tridarmanto, Y. (2008), "Melacak Kembali Metodologi Rasul Paulus dalam berteologi”, Gema Teologi, 32(2), 23. http://journaltheo.ukdw.ac.id/index.php/gema/artic le/view/43.

Verkuyl, J. Aku Percaya. Jakarta: BPK Gunung Mulia, 1995.

Zondervan. New International Dictionary of New Testament Theology 2. USA: Zondervan Academic, 2003.

Zuck, R.B. A Biblical Theology of the New Testament. Chicago: Moody Publishers, 1994. 